\title{
3D Culture Represents Apoptosis Induced by Trastuzumab Better than 2D Monolayer Culture
}

\author{
TAKASHI TATARA ${ }^{1,2}$, TORU MUKOHARA $^{1,3,4}$, RINA TANAKA $^{5}$, YOHEI SHIMONO ${ }^{1,6}$, \\ YOHEI FUNAKOSHI ${ }^{1}$, YOSHINORI IMAMURA ${ }^{1}$, MASANORI TOYODA ${ }^{1}$, \\ NAOMI KIYOTA ${ }^{1,3}$, MIDORI HIRAI ${ }^{5}$, YOSHIHIRO KAKEJI ${ }^{2}$ and HIRONOBU MINAMI ${ }^{1,3}$ \\ ${ }^{1}$ Division of Medical Oncology/Hematology, Department of Medicine, ${ }^{2}$ Division of Gastrointestinal Surgery, \\ Department of Surgery, and Divisions of ${ }^{5}$ Pharmacokinetics and Pharmaceutics and \\ ${ }^{6}$ Molecular and Cellular Biology, Department of Biochemistry and Molecular Biology, \\ Kobe University Graduate School of Medicine, Kobe, Japan; \\ ${ }^{3}$ Cancer Center, Kobe University Hospital, Kobe, Japan; \\ ${ }^{4}$ Division of Breast and Medical Oncology, National Cancer Center Hospital East, Kashiwa, Japan
}

\begin{abstract}
Background: Our hypothesis was that threedimensional $(3 D)$ culture better represents differential in vivo responses to trastuzumab between PIK3CA-wild-type (wt) and mutant ( $\mathrm{mt}$ ) cell lines than does two-dimensional (2D) culture. Materials and Methods: Apoptosis and cell signaling proteins were evaluated in response to trastuzumab with and without BKM120, a pan-phosphatidylinositol 3-kinase (PI3K) inhibitor, using western blot analysis of four breast cancer cell lines with human epidermal growth factor receptor 2 (HER2) amplification. Results: Increased expression of cleaved poly (ADP-ribose) polymerase (PARP) was observed only in 3D-cultured PIK3CA-wt lines in response to trastuzumab, but not in $2 D$-cultured PIK3CA-wt or PIK3CA-mt lines. Decrease in the ratio of phosphorylated ( $p$-)AKT to AKT in response to trastuzumab was more profound in PIK3CA-wt cells than in PIK3CA-mt cells in $3 D$ culture, while the difference between PIK3CA genotypes was less apparent in $2 D$ culture. Treatment with BKM120 and trastuzumab resulted in a stronger increase in cleaved PARP than either treatment alone. Conclusion: $3 D$ Culture appears to better represent trastuzumab-induced apoptosis and resistance to trastuzumab associated with PIK3CA mutation.
\end{abstract}

The incidence of breast cancer is increasing worldwide, with breast cancer accounting for $29 \%$ of all new cancer diagnoses in women (1). The human epidermal growth factor receptor 2

Correspondence to: Toru Mukohara, MD, DMedSci, Division of Breast and Medical Oncology, 6-5-1 Kahiwanoha, Kashiwa 277-8577, Japan. Tel: +81 471331111, Fax: +81 471346922, e-mail: tmukohar@ east.ncc.go.jp

Key Words: Breast cancer, 3D-culture, PIK3CA, trastuzumab.
(HER2) gene is amplified in approximately $20 \%$ of breast cancer cases, and HER 2 overexpression has been recognized as a poor prognostic factor for breast cancer (2). Trastuzumab, a recombinant humanized monoclonal antibody against HER2, inhibits several signaling pathways, such as the phosphatidylinositol 3-kinase (PI3K)-AKT serine/threonine kinase 1 and the rat sarcoma virus (RAS)/rapidly accelerated fibrosarcoma (RAF)/mitogen activated protein kinase kinase (MEK)/extracellular signal regulated kinase (ERK) 1/2 pathways $(3,4)$. Several studies have demonstrated that trastuzumab significantly improved the prognosis of HER2-overexpressing breast cancer cases, not only in the recurrent/metastatic setting but also in the neoadjuvant/adjuvant setting (5-8).

The PIK3CA gene encodes p110 alpha, the catalytic subunit of PI3K. PIK3CA is frequently mutated in breast cancer, with an incidence of $\sim 30 \%$ (9). There are two hotspots of PIK3CA mutation, E542K or E545K in exon 9 and H1047R in exon 20, and both have been shown to function as activating mutations (9). These PIK3CA-activating mutations theoretically cause resistance to trastuzumab, as the PI3K-AKT pathway signaling can be maintained despite the upstream inhibition of HER 2 by trastuzumab $(10,11)$. In fact, large clinical studies that analyzed PIK3CA genotype in patients treated with trastuzumabcontaining chemotherapy in a neoadjuvant setting showed that the rates of pathological complete response of the PIK3CAmutant (mt) group was significantly lower than that of the PIK3CA-wild type (wt) group $(12,13)$. In vitro studies including ours also showed that PIK3CA mutation was associated with resistance to trastuzumab $(14,15)$. However, previous in vitro studies have not clearly shown differential cell signaling changes between PIK3CA-wt and PIK3CA-mt cells following exposure to trastuzumab $(14,15)$. In addition, although tumor shrinkage is occasionally observed in patients treated with trastuzumab as a single agent in the clinic (16), no 
cell death in response to trastuzumab has been observed in vitro as far as we are aware. Notably, all of these in vitro studies have been performed using traditional two-dimensional (2D) cell culture models $(14,15)$.

Three-dimensional (3D) cell culture, in which cells can develop multicellular spheroids, is believed to more accurately mimic in vivo tumor characteristics and the microenvironment compared with 2D cell culture (17). In this study, 3D and 2D cultures using HER2-amplified breast cancer cell lines were compared, under the hypothesis that 3D culture may better represent differential cytological and biochemical responses to trastuzumab between $P I K 3 C A$-wt and PIK3CA-mt cell lines.

\section{Materials and Methods}

Breast cancer cell lines and cell culture. HER2-amplified BT474 and ZR75-30 (PIK3CA-wt) and UACC893 and MDA-MB-361 (PIK3CA$\mathrm{mt})$ breast cancer cell lines were purchased from the American Type Culture Collection (Manassas, VA, USA). Although the BT474 cell line harbors a PIK3CA mutation $(\mathrm{K} 111 \mathrm{~N})$, it was regarded here as PIK3CA-wt because a previous study showed a lack of transformation ability and that the influence on downstream signaling is negligible (14). Cells were maintained in RPMI- $1640^{\circledR}$ (Sigma-Aldrich, St. Louis, MO, USA) supplemented with $10 \%$ fetal bovine serum (FBS; Gemini-Bio-Products, Inc., Woodland, CA, USA), 100 units/ml penicillin, 100 units $/ \mathrm{ml}$ streptomycin, and $2 \mathrm{mM}$ glutamine. Cells were cultured at $37^{\circ} \mathrm{C}$ in a humidified atmosphere with $5 \% \mathrm{CO}_{2}$ and were in logarithmic growth phase upon initiation of experiments.

For 2D culture, cells were plated on Falcon 6-well Tissue Culture Plate ${ }^{\circledR}$ (Corning Inc., NY, USA) and for 3D on $35 \mathrm{~mm}$ NanoCulture dish (ORGANOGENIX, Kanagawa, Japan). Cells were confirmed to form spheroids in $3 \mathrm{D}$ culture using a BZ-X710 ${ }^{\circledR}$ microscope (Keyence, Osaka, Japan) before experimental analyses.

Drugs. Trastuzumab was obtained from the Kobe University Hospital Pharmacy. Before each experiment, trastuzumab was diluted in fresh medium. BKM120, a pan-PI3K inhibitor, was purchased from Enzo Life Sciences (Farmingdale, NY, USA). Stock solutions were prepared in dimethyl sulfoxide (DMSO) and stored at $-20^{\circ} \mathrm{C}$. BKM120 was diluted in fresh medium before each experiment, with final DMSO concentration $<0.1 \%$. Cells were treated with trastuzumab $(10 \mu \mathrm{g} / \mathrm{ml})$ with/without BKM120 $(1 \mu \mathrm{M}$ and $5 \mu \mathrm{M})$ for experimental analyses.

Western blotting. Treated cells were washed once with ice-cold PBS and scraped immediately after adding lysis buffer $[20 \mathrm{mM}$ Tris $(\mathrm{pH}$ 7.5], $150 \mathrm{mM} \mathrm{NaCl}, 2 \mathrm{mM}$ EDTA, $10 \%$ glycerol, and 1\% NP40] containing protease and phosphatase inhibitors $(100 \mathrm{mM} \mathrm{NaF}, 1$ $\mathrm{mM}$ phenylmethylsulfonyl fluoride, $1 \mathrm{mM} \mathrm{Na} \mathrm{VO}_{4}, 2 \mathrm{mg} / \mathrm{ml}$ aprotinin, and $5 \mathrm{mg} / \mathrm{ml}$ leupeptin). Cell lysates were centrifuged at $14,000 \times g$ for $10 \mathrm{~min}$ at $4^{\circ} \mathrm{C}$ to pellet insoluble material, and the supernatants were collected. Aliquots of protein extracts were separated by electrophoresis on precast $7.5 \%$ polyacrylamide gels, followed by transfer to polyvinylidene difluoride membranes. Membranes were probed with the following primary antibodies: HER2/ERBB2 (44E7), phospho-HER2/ERBB2 (Tyr1221/1222) (6B12), AKT (C67E7), phospho-AKT (Ser473) (D9E), or cleaved poly (ADP-ribose) polymerase (PARP) (Asp214) (D64E10) purchased from Cell Signaling Technology (Beverly, MA, USA) or ERK1/2 or phospho-ERK1/2 (pTpY ${ }^{185 / 187}$ ) purchased from Invitrogen (Carlsbad, CA, USA). The blots were stripped and reprobed with a $\beta$-actin antibody (Sigma-Aldrich) for loading control. Bands were detected using Amersham ECL plus Western Blotting Detection Reagents (GE Healthcare, Little Chalfont, Buckinghamshire, UK). Immunoblot quantification was carried out by densitometry using an Amersham Imager 600 (GE Healthcare).

Apoptosis signaling pathway array. BT474 cells were cultured in $2 \mathrm{D}$ or $3 \mathrm{D}$ conditions for $72 \mathrm{~h}$, followed by additional treatment with trastuzumab $(10 \mu \mathrm{g} / \mathrm{ml})$ for another $72 \mathrm{~h}$. Cell lysates were then subjected to analysis using the Human Apoptosis Signaling Pathway Array C1 (RayBiotech, Norcross, GA, USA) following the manufacturer's instructions.

\section{Results}

Trastuzumab induces apoptosis of PIK3CA-wt cells under $3 D$ culture. In order to determine whether $3 \mathrm{D}$ culture conditions would affect breast cancer cell response to trastuzumab in vitro, breast cancer cells were cultured under 2D and 3D conditions for 3 days (Figure 1) before treatment and subsequent experimental analysis (summarized in Figure 2). Cells were then treated with trastuzumab for another 3 days and western blot analysis was performed for cleaved PARP, an indicator of apoptosis (Figure 3). In the PIK3CAwt cell lines, BT474 and ZR75-30, although trastuzumab had no impact on cleaved PARP under 2D conditions, a marked increase of cleaved PARP in response to trastuzumab was detected under 3D culture conditions. However, in PIK3CA$\mathrm{mt}$ cell lines, no cleaved PARP was detected in response to trastuzumab in $2 \mathrm{D}$ or $3 \mathrm{D}$ culture.

Changes in apoptosis and cell signaling proteins induced by trastuzumab. In order to elucidate the differential cytological responses to trastuzumab between 2D- and 3D-cultured PIK3CA-wt cells, protein lysates from BT474 cells grown with and without trastuzumab were subjected to analysis using the Human Apoptosis Signaling Pathway Array C1. Treatment with trastuzumab led to the reduction of p-AKT (Ser-473) expression under both 2D and 3D conditions (Figure 4). Notably, the expression of cleaved caspase-3 (Asp175), indicative of activation of pro-apoptotic caspase-3, was higher in $3 \mathrm{D}$ culture than in $2 \mathrm{D}$ culture, even in the absence of trastuzumab. These findings suggested that BT474 cells are under pro-apoptotic conditions in 3D culture compared with 2D culture, and that apoptosis induced by trastuzumab coincides with inhibition of the PI3K-AKT pathway.

In order to further explore the molecular mechanisms underlying the differential cytological responses to trastuzumab between PIK3CA-wt and-mt cell lines in 2D and 3D cultures, the expression of p-AKT was examined using western blot (Figure 5). In PIK3CA-wt BT474 cells, the ratio of p-AKT to 


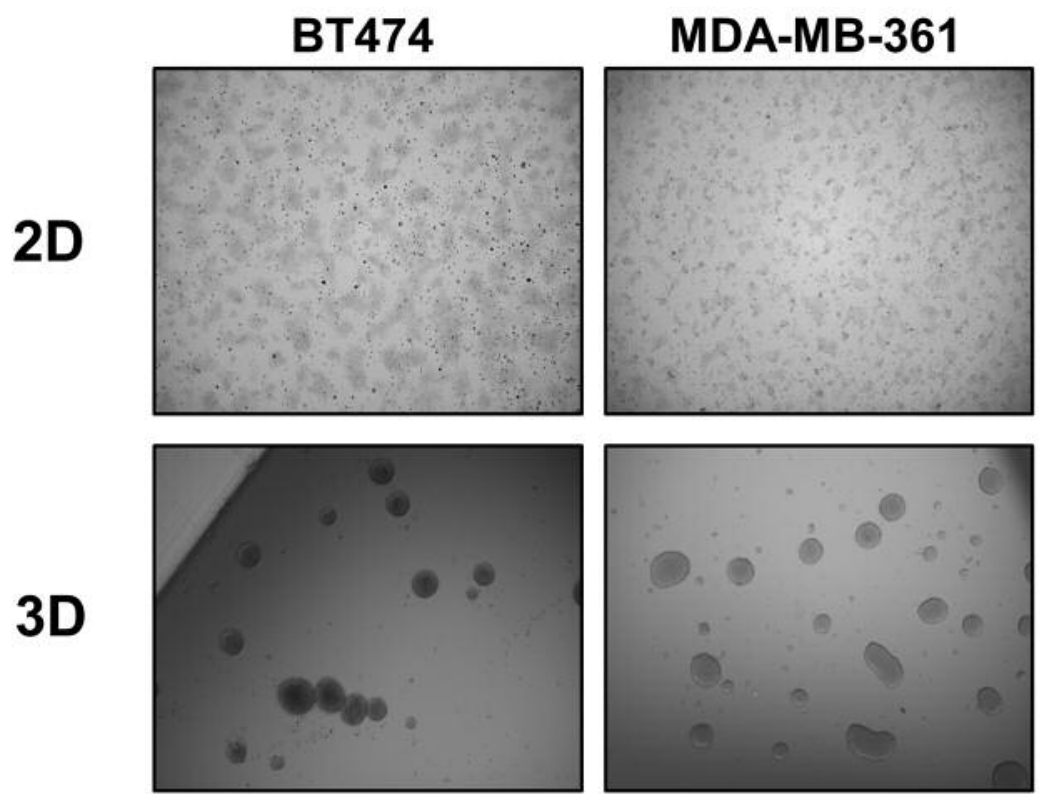

Figure 1. Spheroid formation in 3D cell culture. Bright-field images of BT474 and MDA-MB-361 cells grown in 2D and 3D conditions were captured 3 days after cell seeding.

AKT was reduced both in $2 \mathrm{D}$ and $3 \mathrm{D}$ culture in response to trastuzumab over time, while a similar reduction was observed in response to trastuzumab only in $3 \mathrm{D}$ culture for the PIK3CAwt cell line ZR75-30. In contrast, in the PIK3CA-mt cell lines, the ratio of p-AKT to AKT was reduced to a lower extent under both cell culture conditions compared with 3D-cultured PIK3CA-wt cell lines. These findings suggest that suppression of the PI3K-AKT pathway is necessary but not sufficient to induce apoptosis in HER2-amplified cell lines.

The PI3K inhibitor BKM120 enhances apoptosis induced by trastuzumab in breast cancer cell lines. Because inhibition of the PI3K-AKT pathway was suggested to be essential for apoptosis induced by trastuzumab under 3D culture conditions, we next tested if BKM120, a pan-PI3K inhibitor, was able to induce apoptosis. In all cell lines except UACC 893 , treatment with $1 \mu \mathrm{M}$ BKM120 resulted in an increase in cleaved PARP (Figure 6). In UACC893 cells, a higher concentration of BKM120 $(5 \mu \mathrm{M})$ was required to induce a detectable increase in cleaved PARP, whereas it was not possible to collect a sufficient amount of cell lysate from MDA-MB-361 and ZR75-30 cells treated with $5 \mu \mathrm{M}$ BKM120, likely because of prominent apoptosis. In all cell lines, trastuzumab combined with BKM120 led to a greater increase in cleaved PARP compared with either drug alone. These results suggest that BKM120 not only overcomes resistance to trastuzumab observed in PIK $3 C A$-mt cells, but also enhances the pro-apoptotic effect of trastuzumab.

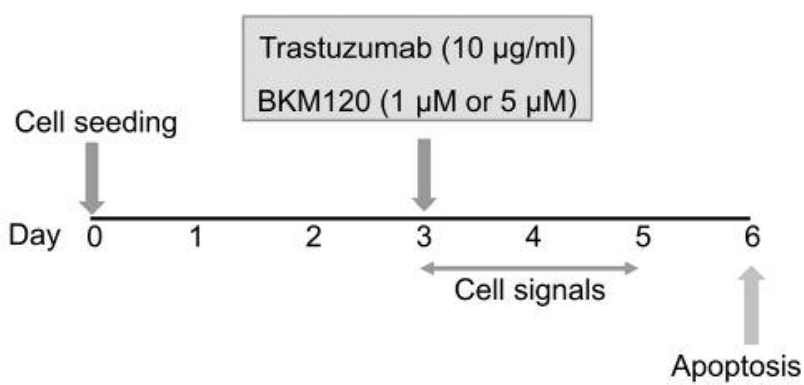

Figure 2. Experimental scheme. The human epidermal growth factor receptor 2 (HER2)-amplified breast cancer cell lines BT474 and ZR7530 [both phosphatidylinositol 3-kinase CA (PI3KCA) wild-type], and UACC893 and MDA-MB-361 (both PIK3CA-mutant) were seeded (day $0)$ and cultured in $2 D$ or $3 D$ cell culture plates. On day 3 , trastuzumab $(10 \mu \mathrm{g} / \mathrm{ml})$, with/without pan-PI3K inhibitor BKM120 (1 and $5 \mu \mathrm{M})$, was added. Cell signaling pathways were examined by western blot on days 3 through 5, and apoptosis was evaluated by western blot on day 6 .

\section{Discussion}

In this study, trastuzumab was demonstrated to induce apoptosis only in HER2-amplified and PIK3CA-wt breast cancer cell lines cultured under 3D conditions, but not in these cell lines under 2D conditions, nor in PIK3CA-mt cell lines regardless of cell culture conditions. The apoptotic effect of trastuzumab in 3D-cultured PIK3CA-wt lines also 


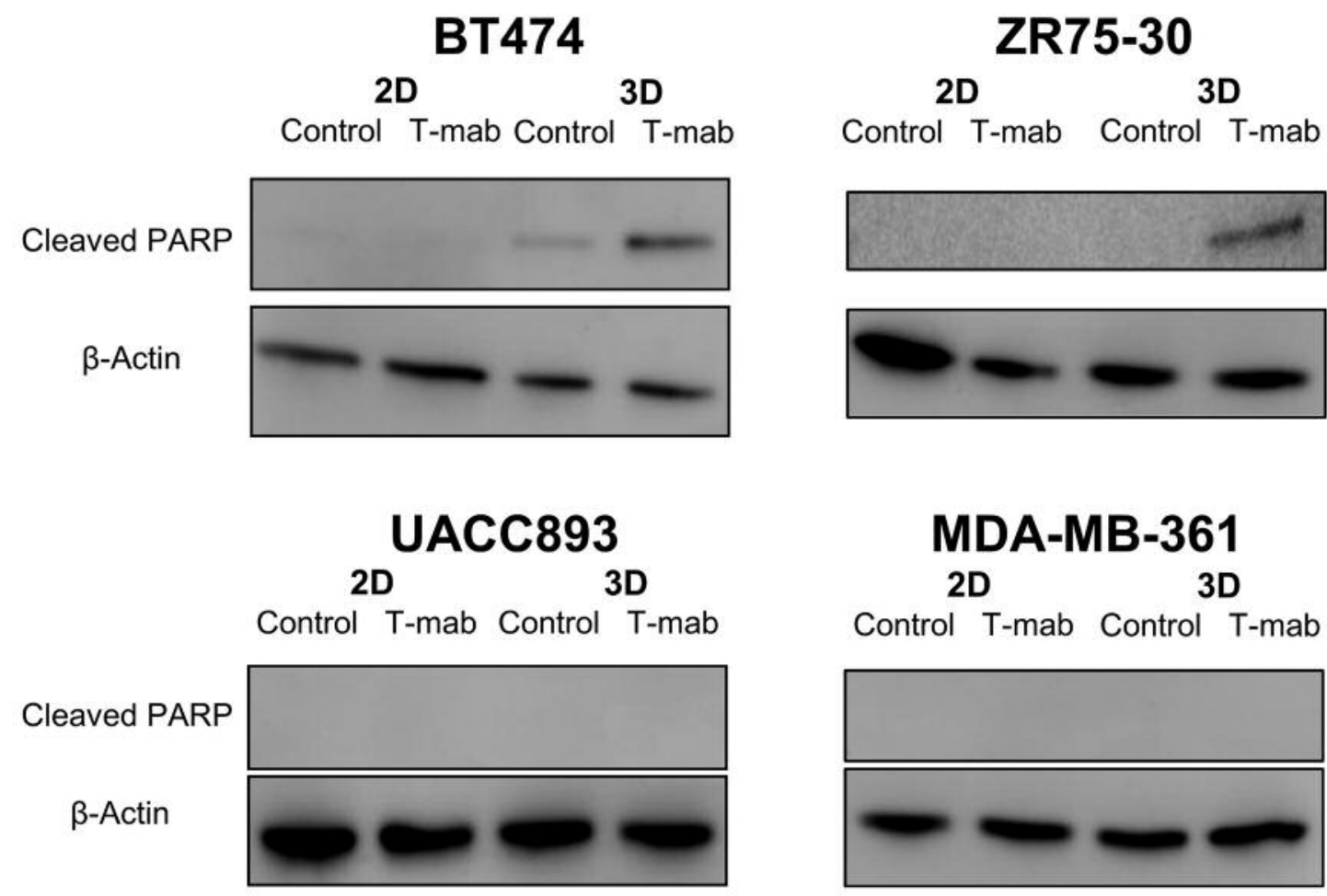

Figure 3. Effect of trastuzumab on poly (ADP-ribose) polymerase (PARP) cleavage in $2 D$-and $3 D$-cultured breast cancer cell lines. Four breast cancer cell lines were cultured under $2 D$ or $3 D$ culture conditions for 3 days. Cells were then cultured without (Control) or with $10 \mu \mathrm{g} / \mathrm{ml}$ trastuzumab (T-mab) for another 3 days and then subjected to western blot analysis for expression of cleaved PARP.

appears to be a phenomenon associated with inhibition of the PI3K-AKT pathway that takes place in pro-apoptotic conditions.

Our result is consistent with previous pre-clinical studies showing that HER2-amplified breast cancer cell lines are more sensitive to trastuzumab in $3 \mathrm{D}$ culture than in $2 \mathrm{D}$ culture $(18,19)$. However, Weigelt et al. concluded that the effect of trastuzumab remained cytostatic even in 3D culture using AU565, SKBR3, and HCC1569 HER2-amplified cell lines (30), in contrast with our results for BT474 and ZR7530 cells cultured under 3D conditions (Figure 3). These different results may be due to different cell lines or different $3 \mathrm{D}$ culture systems. We did not use SKBR3 cell line because these cells were found not to generate solid multicellular spheroids in our system (17). Furthermore, AU565, SKBR3, and HCC1569 cells are all estrogen receptor (ER)-negative, while BT474 and ZR75-30 are both ER-positive (20, 21), which may have affected our results. Although further study is required to demonstrate that the apoptotic effect of trastuzumab observed in 3D-cultured BT474 and ZR75-30 cells actually represents in vivo effects, we believe this conclusion is plausible because trastuzumab treatment was found to reduce the volume of BT474 xenografts in multiple studies $(22,23)$ and trastuzumab as a single agent produced an approximate $30 \%$ response rate in the clinic (16).

Notably, previous studies including ours suggested that results from $2 \mathrm{D}$ culture tend to overestimate drug effects compared with 3D culture in the case of conventional cytotoxic anticancer drugs $(17,24-26)$. However, this trend is in contrast with $2 \mathrm{D}$ and $3 \mathrm{D}$ studies on trastuzumab (18, 19), as well as our current study. One potential explanation for this difference is the difference in signal transduction pathways between $2 \mathrm{D}$ and $3 \mathrm{D}$ cultures. In fact, previous study showed enhanced AKT- mammalian target of rapamycin (mTOR)-S6K signaling in 2D culture compared with 3D culture (27). Other studies reported that HER2amplified cell lines maintained in 3D culture shift from PI3K-AKT signaling to the mitogen-activated protein kinase (MAPK) pathway $(18,19,28)$. In these reports, there was a modest p-AKT signal observed in 3D culture regardless of exposure to trastuzumab. In our study, we did not observe such AKT to MAPK 'switching' in any of the HER2amplified cell lines tested (Figure 5). The precise cause of the differences between these studies is unknown at this point, but these results indicate that $3 \mathrm{D}$ culture systems may not be uniform in representing cell signaling. 


\section{A Array Map}

\begin{tabular}{|c|c|c|c|c|c|c|c|c|}
\hline & A & B & C & D & E & $\mathbf{F}$ & G & $\mathbf{H}$ \\
\hline 1 & \multirow[t]{2}{*}{ POS } & \multirow[t]{2}{*}{ POS } & \multirow[t]{2}{*}{ NEG } & \multirow{2}{*}{$\begin{array}{c}\text { AKT } \\
(\mathrm{P}-\text { Ser473) }\end{array}$} & \multirow{2}{*}{$\begin{array}{c}\text { ATM } \\
\text { (P-Ser1981) }\end{array}$} & \multirow{2}{*}{$\begin{array}{c}\text { BAD } \\
(\mathrm{P}-\text { Ser112) }\end{array}$} & \multirow{2}{*}{$\begin{array}{c}\text { Caspase-3 } \\
\text { (Cleaved Asp175) }\end{array}$} & \multirow{2}{*}{$\begin{array}{c}\text { Caspase-7 } \\
\text { (Cleaved Asp198) }\end{array}$} \\
\hline 2 & & & & & & & & \\
\hline 3 & \multirow{2}{*}{$\begin{array}{c}\text { CHK1 } \\
(\text { P-Ser296) }\end{array}$} & \multirow{2}{*}{$\begin{array}{c}\text { CHK2 } \\
(\mathrm{P}-\text { Thr68) }\end{array}$} & \multirow{2}{*}{$\begin{array}{c}\text { elF-2a } \\
(\mathrm{P}-\mathrm{Ser} 51)\end{array}$} & \multirow{2}{*}{$\begin{array}{l}\text { ERK1(P-T202/Y204) } \\
\text { ERK2(P-Y185/Y187) }\end{array}$} & \multirow{2}{*}{$\begin{array}{c}\text { HSP27 } \\
(\mathrm{P}-\text { Ser82) }\end{array}$} & \multirow{2}{*}{$\begin{array}{c}\text { IKBa } \\
(\mathrm{P}-\mathrm{Ser} 32)\end{array}$} & \multirow{2}{*}{$\begin{array}{c}\text { JNK } \\
\text { (P-Thr183/Tyr185) }\end{array}$} & \multirow{2}{*}{$\begin{array}{l}\text { NFKBP65 } \\
\text { (P-Ser536) }\end{array}$} \\
\hline 4 & & & & & & & & \\
\hline 5 & \multirow{2}{*}{$\begin{array}{c}\text { PARP1 } \\
\text { (Cleaved Asp214/Gly215) }\end{array}$} & \multirow{2}{*}{$\begin{array}{c}\text { p27 } \\
\text { (P-Thr198) }\end{array}$} & \multirow{2}{*}{$\begin{array}{c}\text { P38 } \\
\text { (P-Thr/180/Tyr182)) }\end{array}$} & \multirow{2}{*}{$\begin{array}{c}\text { P53 } \\
\text { (P-Ser15) }\end{array}$} & \multirow{2}{*}{$\begin{array}{c}\text { SMAD2 } \\
\text { (P-Ser245/250/255) }\end{array}$} & \multirow{2}{*}{$\begin{array}{c}\text { TAK1 } \\
(\mathrm{P}-\mathrm{Ser} 412)\end{array}$} & \multirow[t]{2}{*}{ NEG } & \multirow[t]{2}{*}{ POS } \\
\hline 6 & & & & & & & & \\
\hline
\end{tabular}
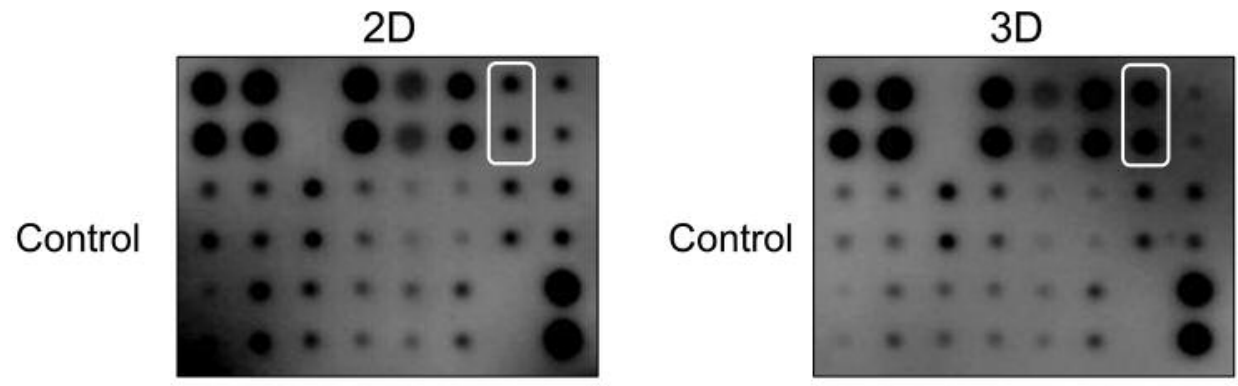

T-mab
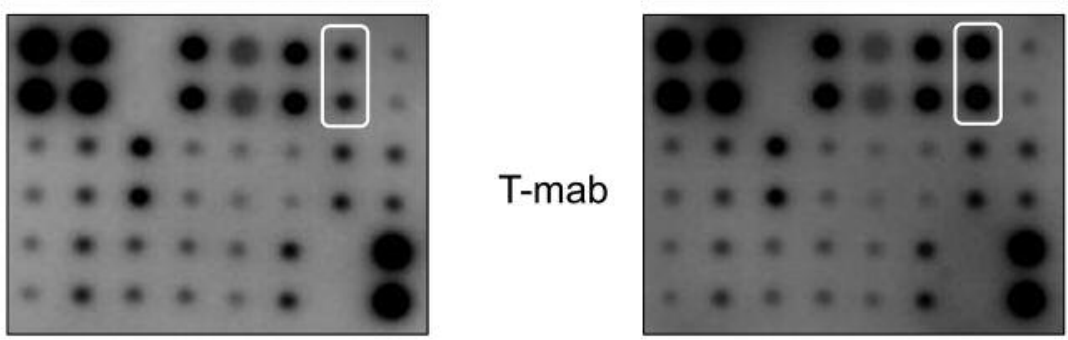

B

Array signals quantified as a percentage that of the positive control

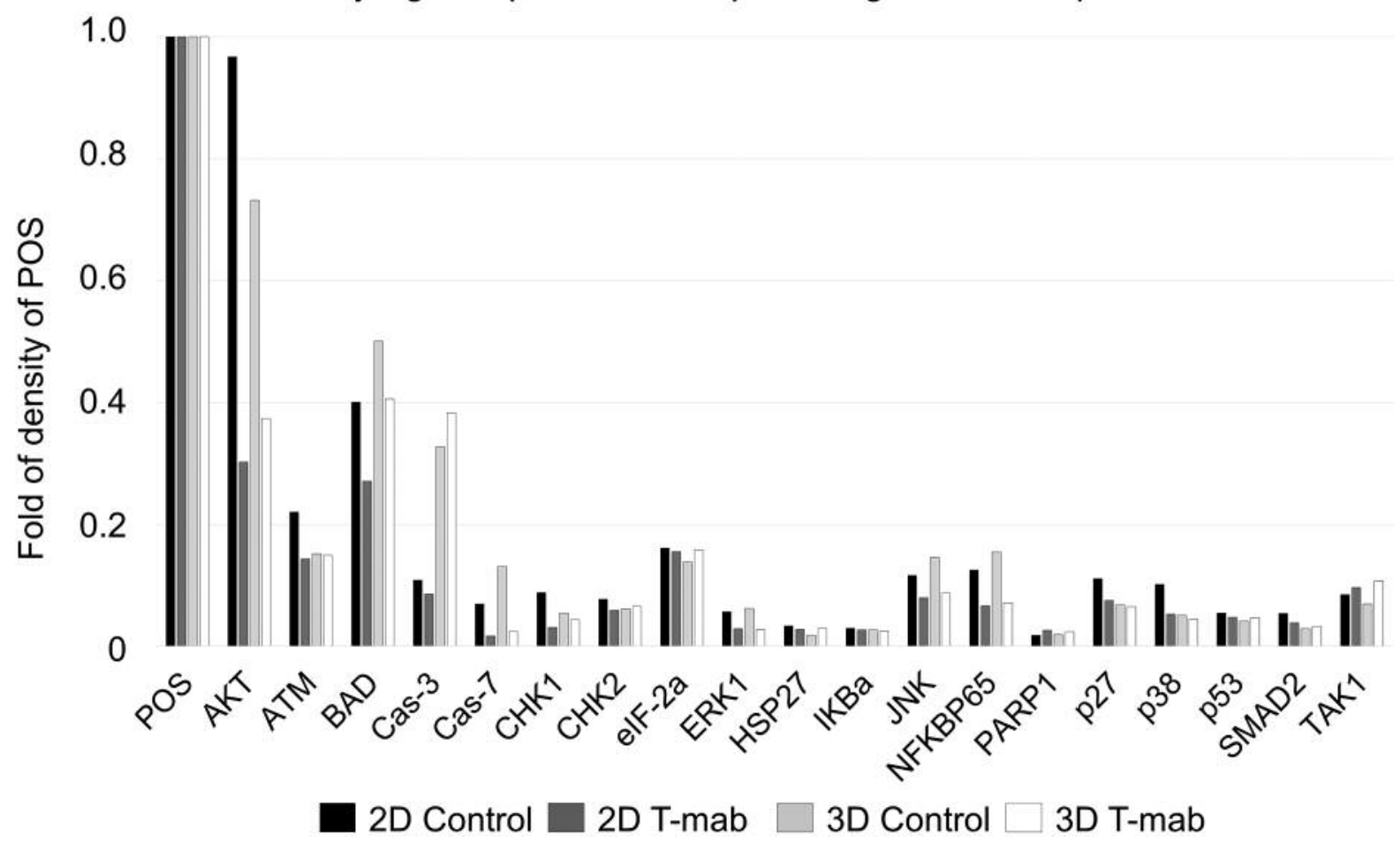

Figure 4. Analysis of BT474 cells using the Human Apoptosis Signaling Pathway Array C1. BT474 cells were cultured in 2D or 3D culture conditions for 3 days and then cultured without (Control) or with $10 \mu \mathrm{g} / \mathrm{ml}$ trastuzumab (T-mab) for another 3 days. Lysates were then analyzed using the Human Apoptosis Signaling Pathway Array C1. A: Array results from BT474 cells cultured as indicated. The dotted line indicates cleaved caspase 3. B: Array signals were quantified and plotted on the $y$-axis as a percentage to that of the positive control (POS). NEG: Negative control, Cas-3: Caspase- 3, Cas-7; Caspase-7. 
A

A
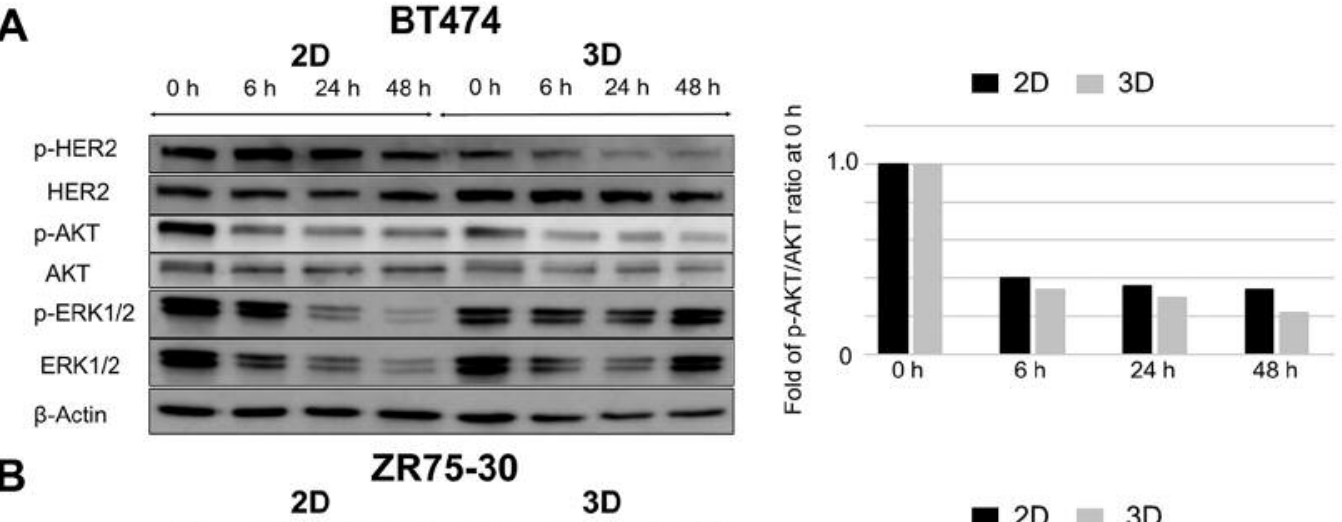

B
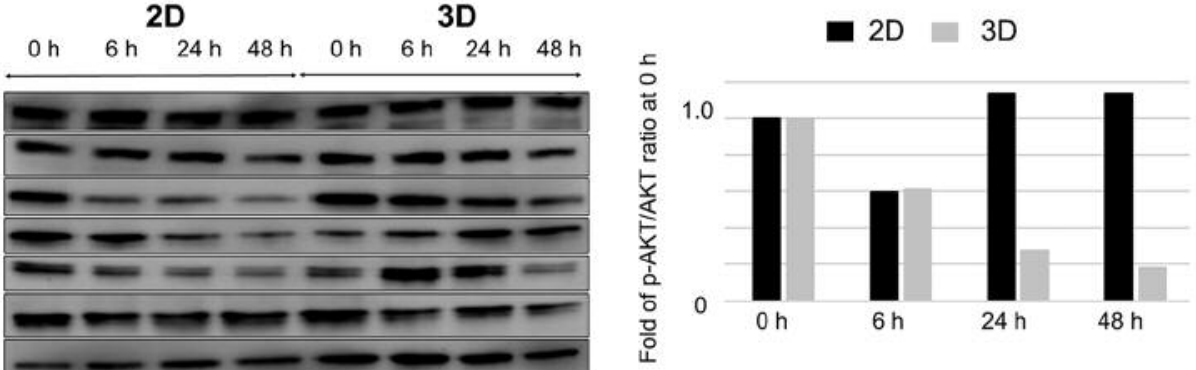

C

UACC893

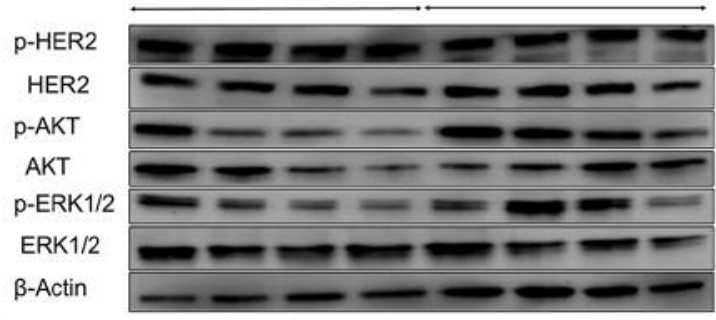

$\beta$-Actin

3D
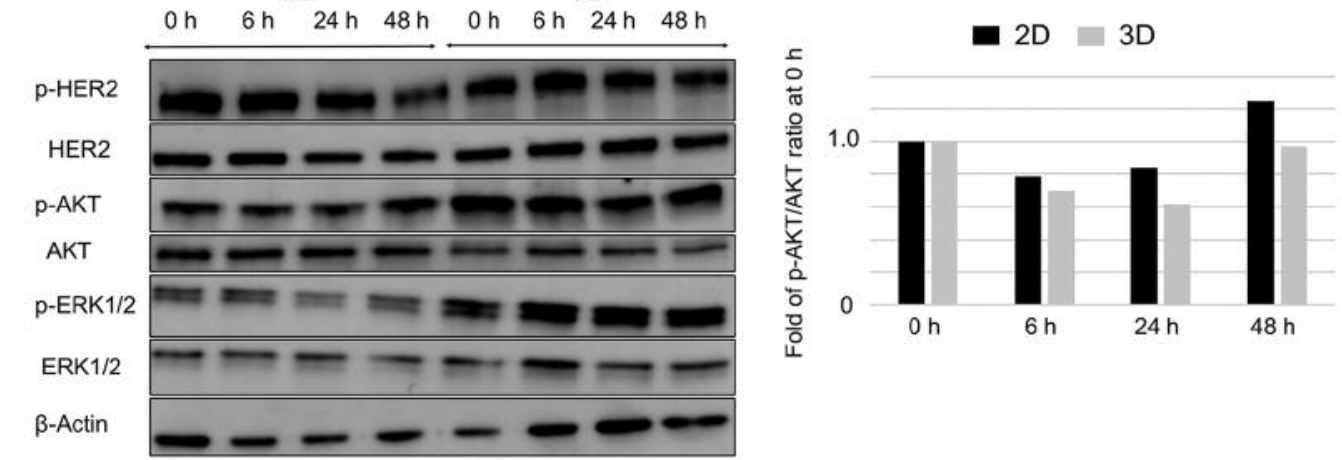

D

MDA-MB-361

2D

3D
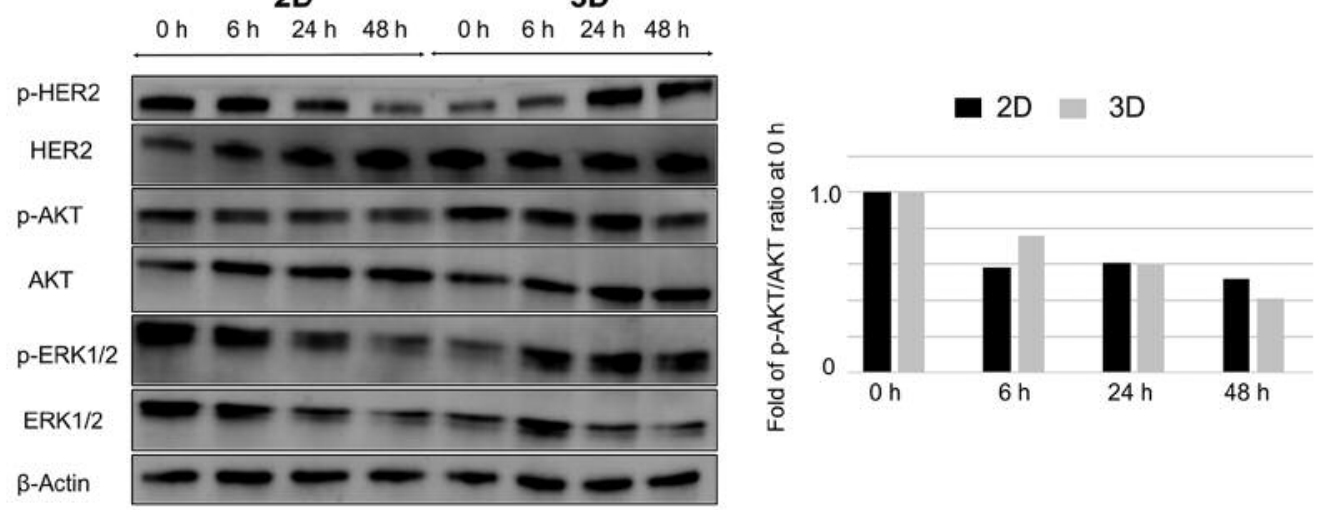

Figure 5. Effect of trastuzumab on cell signaling in $2 D$ - and 3D-cultured breast cancer cell lines. Breast cancer cells were cultured under $2 D$ or $3 D$ conditions and then treated with $10 \mu \mathrm{g} / \mathrm{ml}$ trastuzumab for 6, 24, or $48 \mathrm{~h}$. A: BT474, B: ZR75-30, C: UACC893, and D: MDA-MB-361. Left, western blots of signaling proteins. Right, Bands for phosphorylated ( $p-)$ AKT serinelthreonine kinase-1 (AKT) and AKT were quantified and the ratio of p-AKT to AKT at each time point was plotted on the y-axis as a percentage that of the control $(0 \mathrm{~h})$. ERK: Extracellular signal regulated kinase; HER2: human epidermal growth factor receptor 2. 
BT474

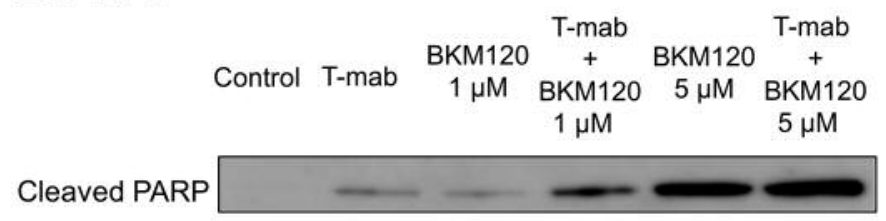

$\beta$-Actin

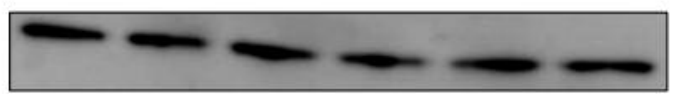

ZR75-30

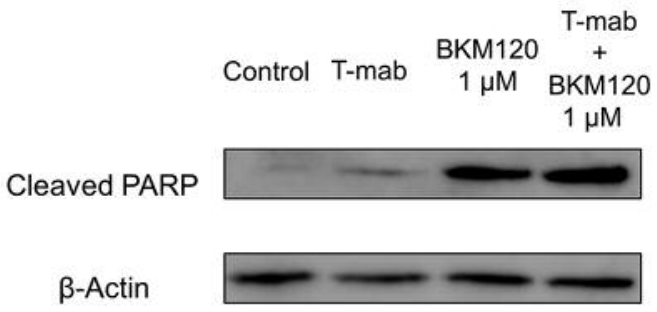

UACC893

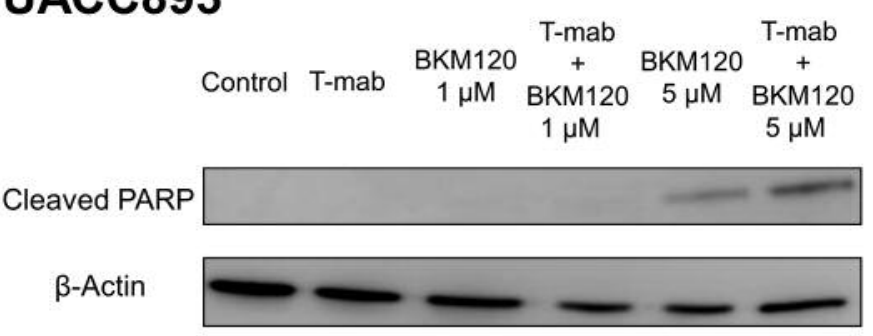

MDA-MB-361

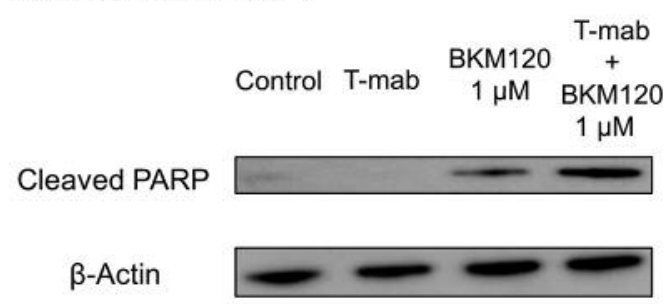

Figure 6. Effect of trastuzumab and BKM120 on expression of poly (ADP-ribose) polymerase (PARP) in 3D-cultured breast cancer cell lines. Four breast cancer cell lines were cultured under $3 D$ culture for 3 days, followed by treatment with or without $10 \mu g / m l$ trastuzumab (T-mab) with/without $1 \mu M$ or $5 \mu M$ BKM120 for another 3 days. Western blot analysis was performed for cleaved PARP.

The current finding that BT474 cells have higher expression of cleaved caspase- 3 in $3 \mathrm{D}$ culture than in $2 \mathrm{D}$ is consistent with a previous report by Breslin et al., who showed increased expression of pro-apoptotic caspase-3, -7, and -9 in 3D-cultured breast cancer cell lines, including BT474 cells, compared with 2D-cultured cells (29). In contrast, our previous study using BT474 cells and cells obtained from a breast cancer patient-derived xenograft showed that expression of caspase-3 was higher in 2Dcultured cells than the 3D-cultured counterparts (17). Although no clear explanation for these somewhat inconsistent findings is available, we believe that the level of cleaved caspase- 3 represents the pro-apoptotic status of the cells better than that of full length caspase-3, because cleaved caspase-3 is a more functional marker (30).

BKM120 is pan-PI3K inhibitor that inhibits all four isoforms of class I PI3K $(\alpha, \beta, \delta$, and $\gamma)(31)$. A clinical phase Ib study of BKM120 plus trastuzumab in patients with HER2positive advanced and metastatic breast cancer demonstrated the clinical activity of this combination, with a disease control rate of $75 \%$ (32). Our current findings also suggest that BKM120 may overcome trastuzumab resistance caused by PIK3CA mutation (Figure 6). However, a recently reported randomized phase II study of BKM120 versus placebo combined with trastuzumab and paclitaxel in neoadjuvant settings failed to show an increased pathological response rate by adding BKM120 to the backbone combination therapy, even in a PIK3CA-mt population (33). However, this result was considered inconclusive because only four patients with PIK3CA mutation were enrolled in each BKM120 and placebo arm in the study. However, the report did show an increased response rate by adding BKM120 versus placebo to trastuzumab and paclitaxel only in the ER-positive/HER2positive population but not in the ER-negative/HER2-positive population. Among the four HER2-amplified cell lines tested in our study, only UACC893 cells were ER-negative, and this cell line appeared to be relatively unresponsive to BKM120 compared with the others, consistent with the findings of the phase II study above.

Our study had some limitations. Firstly, we used only four cell lines, and thus further investigation using more cell lines is necessary to verify our results. Secondly, it is possible that the cell lines may have lost their original tumor characteristics. In order to exclude this possibility, a primary culture or patient-derived xenograft should be experimentally examined. Thirdly, trastuzumab is rarely used as a single agent in the clinic. Thus, the utility of $3 \mathrm{D}$ culture in evaluating a more clinically relevant combination therapy with chemotherapeutic drugs or other anti-HER2 drugs, such as pertuzumab and lapatinib, should be tested.

In conclusion, our results indicate that $3 \mathrm{D}$ cell culture appears to better represent trastuzumab-induced apoptosis 
and resistance to trastuzumab associated with PIK3CA mutation in HER2-amplified breast cancer cells.

\section{Conflicts of Interest}

The Authors declare that they have no conflicts of interest in regard to this study.

\section{Acknowledgements}

The Authors thank ORGANOGENIX inc. for providing NanoCulture plates and useful discussion, Edanz Group (www.edanzediting.com/ac) for editing a draft of this article. This study was supported by the Grant-in-Aid for Scientific Research (C) (T.M.).

\section{References}

1 Siegel RL, Miller KD and Jemal A: Cancer statistics, 2016. CA Cancer J Clin 66(1): 7-30, 2016.

2 Slamon DJ, Clark GM, Wong SG, Levin WJ, Ullrich A and McGuire WL: Human breast cancer: Correlation of relapse and survival with amplification of the her- $2 /$ neu oncogene. Science 235(4785): 177-182, 1987.

3 Gemmete JJ and Mukherji SK: Trastuzumab (herceptin). AJNR Am J Neuroradiol 32(8): 1373-1374, 2011.

4 Yakes FM, Chinratanalab W, Ritter CA, King W, Seelig S and Arteaga CL: Herceptin-induced inhibition of phosphatidylinositol-3 kinase and akt is required for antibody-mediated effects on p27, cyclin d1, and antitumor action. Cancer Res 62(14): 4132-4141, 2002.

5 Smith I, Procter M, Gelber RD, Guillaume S, Feyereislova A, Dowsett M, Goldhirsch A, Untch M, Mariani G, Baselga J, Kaufmann M, Cameron D, Bell R, Bergh J, Coleman R, Wardley A, Harbeck N, Lopez RI, Mallmann P, Gelmon K, Wilcken N, Wist E, Sanchez Rovira P, Piccart-Gebhart MJ and Hera Study Team: 2-year follow-up of trastuzumab after adjuvant chemotherapy in her2-positive breast cancer: A randomised controlled trial. Lancet 369(9555): 29-36, 2007.

6 Joensuu H, Kellokumpu-Lehtinen PL, Bono P, Alanko T, Kataja V, Asola R, Utriainen T, Kokko R, Hemminki A, Tarkkanen M, Turpeenniemi-Hujanen T, Jyrkkio S, Flander M, Helle L, Ingalsuo S, Johansson K, Jaaskelainen AS, Pajunen M, Rauhala M, Kaleva-Kerola J, Salminen T, Leinonen M, Elomaa I, Isola $\mathrm{J}$ and FinHer Study Investigators: Adjuvant docetaxel or vinorelbine with or without trastuzumab for breast cancer. $\mathrm{N}$ Engl J Med 354(8): 809-820, 2006.

7 Buzdar AU, Ibrahim NK, Francis D, Booser DJ, Thomas ES, Theriault RL, Pusztai L, Green MC, Arun BK, Giordano SH, Cristofanilli M, Frye DK, Smith TL, Hunt KK, Singletary SE, Sahin AA, Ewer MS, Buchholz TA, Berry D and Hortobagyi GN: Significantly higher pathologic complete remission rate after neoadjuvant therapy with trastuzumab, paclitaxel, and epirubicin chemotherapy: Results of a randomized trial in human epidermal growth factor receptor 2-positive operable breast cancer. J Clin Oncol 23(16): 3676-3685, 2005.

8 Gianni L, Eiermann W, Semiglazov V, Manikhas A, Lluch A, Tjulandin S, Zambetti M, Vazquez F, Byakhow M, Lichinitser M, Climent MA, Ciruelos E, Ojeda B, Mansutti M, Bozhok A, Baronio R, Feyereislova A, Barton C, Valagussa P and Baselga
J: Neoadjuvant chemotherapy with trastuzumab followed by adjuvant trastuzumab versus neoadjuvant chemotherapy alone, in patients with her2-positive locally advanced breast cancer (the noah trial): A randomised controlled superiority trial with a parallel her2-negative cohort. Lancet 375(9712): 377-384, 2010.

9 Mukohara T: Pi3k mutations in breast cancer: Prognostic and therapeutic implications. Breast Cancer (Dove Med Press) 7: 111-123, 2015.

10 Nahta R, Yu D, Hung MC, Hortobagyi GN and Esteva FJ: Mechanisms of disease: Understanding resistance to her2targeted therapy in human breast cancer. Nat Clin Pract Oncol 3(5): 269-280, 2006.

11 Wang Q, Liu P, Spangle JM, Von T, Roberts TM, Lin NU, Krop IE, Winer EP and Zhao JJ: Pi3k-p110alpha mediates resistance to her2-targeted therapy in her2+, pten-deficient breast cancers. Oncogene 35(27): 3607-3612, 2016.

12 Majewski IJ, Nuciforo P, Mittempergher L, Bosma AJ, Eidtmann H, Holmes E, Sotiriou C, Fumagalli D, Jimenez J, Aura C, Prudkin L, Diaz-Delgado MC, de la Pena L, Loi S, Ellis C, Schultz N, de Azambuja E, Harbeck N, Piccart-Gebhart M, Bernards R and Baselga J: Pik3ca mutations are associated with decreased benefit to neoadjuvant human epidermal growth factor receptor 2-targeted therapies in breast cancer. J Clin Oncol 33(12): 1334-1339, 2015.

13 Loibl S, von Minckwitz G, Schneeweiss A, Paepke S, Lehmann A, Rezai M, Zahm DM, Sinn P, Khandan F, Eidtmann H, Dohnal K, Heinrichs C, Huober J, Pfitzner B, Fasching PA, Andre F, Lindner JL, Sotiriou C, Dykgers A, Guo S, Gade S, Nekljudova V, Loi S, Untch $M$ and Denkert C: Pik3ca mutations are associated with lower rates of pathologic complete response to anti-human epidermal growth factor receptor 2 (her2) therapy in primary her2-overexpressing breast cancer. J Clin Oncol 32(29): 3212-3220, 2014.

14 Kataoka Y, Mukohara T, Shimada H, Saijo N, Hirai M and Minami H: Association between gain-of-function mutations in pik3ca and resistance to her2-targeted agents in her2-amplified breast cancer cell lines. Ann Oncol 21(2): 255-262, 2010.

15 Berns K, Horlings HM, Hennessy BT, Madiredjo M, Hijmans EM, Beelen K, Linn SC, Gonzalez-Angulo AM, Stemke-Hale K, Hauptmann M, Beijersbergen RL, Mills GB, van de Vijver MJ and Bernards R: A functional genetic approach identifies the pi3k pathway as a major determinant of trastuzumab resistance in breast cancer. Cancer Cell 12(4): 395-402, 2007.

16 Vogel CL, Cobleigh MA, Tripathy D, Gutheil JC, Harris LN, Fehrenbacher L, Slamon DJ, Murphy M, Novotny WF, Burchmore M, Shak S, Stewart SJ and Press M: Efficacy and safety of trastuzumab as a single agent in first-line treatment of her2-overexpressing metastatic breast cancer. J Clin Oncol 20(3): 719-726, 2002.

17 Imamura Y, Mukohara T, Shimono Y, Funakoshi Y, Chayahara N, Toyoda M, Kiyota N, Takao S, Kono S, Nakatsura T and Minami $\mathrm{H}$ : Comparison of $2 \mathrm{~d}$ - and $3 \mathrm{~d}$-culture models as drug-testing platforms in breast cancer. Oncol Rep 33(4): 1837-1843, 2015.

18 Weigelt B, Lo AT, Park CC, Gray JW and Bissell MJ: Her2 signaling pathway activation and response of breast cancer cells to her2-targeting agents is dependent strongly on the $3 \mathrm{~d}$ microenvironment. Breast Cancer Res Treat 122(1): 35-43, 2010.

19 Pick1 M and Ries CH: Comparison of $3 \mathrm{~d}$ and $2 \mathrm{~d}$ tumor models reveals enhanced her 2 activation in $3 \mathrm{~d}$ associated with an increased response to trastuzumab. Oncogene 28(3): 461-468, 2009. 
20 Lacroix M and Leclercq G: Relevance of breast cancer cell lines as models for breast tumours: An update. Breast Cancer Res Treat 83(3): 249-289, 2004.

21 Neve RM, Chin K, Fridlyand J, Yeh J, Baehner FL, Fevr T, Clark L, Bayani N, Coppe JP, Tong F, Speed T, Spellman PT, DeVries S, Lapuk A, Wang NJ, Kuo WL, Stilwell JL, Pinkel D, Albertson DG, Waldman FM, McCormick F, Dickson RB, Johnson MD, Lippman M, Ethier S, Gazdar A and Gray JW: A collection of breast cancer cell lines for the study of functionally distinct cancer subtypes. Cancer Cell 10(6): 515-527, 2006.

22 Zhang S, Huang WC, Li P, Guo H, Poh SB, Brady SW, Xiong Y, Tseng LM, Li SH, Ding Z, Sahin AA, Esteva FJ, Hortobagyi GN and Yu D: Combating trastuzumab resistance by targeting src, a common node downstream of multiple resistance pathways. Nat Med 17(4): 461-469, 2011.

23 Purcell JW, Davis J, Reddy M, Martin S, Samayoa K, Vo H, Thomsen K, Bean P, Kuo WL, Ziyad S, Billig J, Feiler HS, Gray JW, Wood KW and Cases S: Activity of the kinesin spindle protein inhibitor ispinesib (sb-715992) in models of breast cancer. Clin Cancer Res 16(2): 566-576, 2010.

24 Karlsson H, Fryknas M, Larsson R and Nygren P: Loss of cancer drug activity in colon cancer hct-116 cells during spheroid formation in a new 3-d spheroid cell culture system. Exp Cell Res 318(13): 1577-1585, 2012.

25 Vinci M, Gowan S, Boxall F, Patterson L, Zimmermann M, Court W, Lomas C, Mendiola M, Hardisson D and Eccles SA: Advances in establishment and analysis of three-dimensional tumor spheroid-based functional assays for target validation and drug evaluation. BMC Biol 10: 29, 2012.

26 Lee JM, Mhawech-Fauceglia P, Lee N, Parsanian LC, Lin YG, Gayther SA and Lawrenson K: A three-dimensional microenvironment alters protein expression and chemosensitivity of epithelial ovarian cancer cells in vitro. Lab Invest 93(5): 528542, 2013

27 Riedl A, Schlederer M, Pudelko K, Stadler M, Walter S, Unterleuthner D, Unger C, Kramer N, Hengstschlager M, Kenner L, Pfeiffer D, Krupitza G and Dolznig H: Comparison of cancer cells in $2 \mathrm{~d}$ vs $3 \mathrm{~d}$ culture reveals differences in aktmtor-s6k signaling and drug responses. J Cell Sci 130(1): 203218,2017

28 Gangadhara S, Smith C, Barrett-Lee P and Hiscox S: 3d culture of her2+ breast cancer cells promotes akt to mapk switching and a loss of therapeutic response. BMC Cancer 16: 345, 2016.
29 Breslin S and O'Driscoll L: The relevance of using 3d cell cultures, in addition to $2 \mathrm{~d}$ monolayer cultures, when evaluating breast cancer drug sensitivity and resistance. Oncotarget 7 : 45745-45756, 2016.

30 Nicholson DW, Ali A, Thornberry NA, Vaillancourt JP, Ding CK, Gallant M, Gareau Y, Griffin PR, Labelle M, Lazebnik YA, Munday NA, Raju SM, Smulson ME, Yamin T-T, Yu VL and Miller DK: Identification and inhibition of the ice/ced-3 protease necessary for mammalian apoptosis. Nature 376(6535): 37-43, 1995.

31 Maira SM, Pecchi S, Huang A, Burger M, Knapp M, Sterker D, Schnell C, Guthy D, Nagel T, Wiesmann M, Brachmann S, Fritsch C, Dorsch M, Chene P, Shoemaker K, De Pover A, Menezes D, Martiny-Baron G, Fabbro D, Wilson CJ, Schlegel R, Hofmann F, Garcia-Echeverria C, Sellers WR and Voliva CF: Identification and characterization of nvp-bkm120, an orally available pan-class i pi3-kinase inhibitor. Mol Cancer Ther 11(2): 317-328, 2012.

32 Saura C, Bendell J, Jerusalem G, Su S, Ru Q, De Buck S, Mills D, Ruquet S, Bosch A, Urruticoechea A, Beck JT, Di Tomaso E, Sternberg DW, Massacesi C, Hirawat S, Dirix L and Baselga J: Phase ib study of buparlisib plus trastuzumab in patients with her2-positive advanced or metastatic breast cancer that has progressed on trastuzumab-based therapy. Clin Cancer Res 20(7): 1935-1945, 2014.

33 Loibl S, de la Pena L, Nekljudova V, Zardavas D, Michiels S, Denkert C, Rezai M, Bermejo B, Lee S-C, Turri S, Urban P, Kümmel S, Lux M, Piccart M, von Minckwitz G, Baselga J and Loi S: Phase II, randomized, parallel-cohort study of neoadjuvant buparlisib (bkm120) in combination with trastuzumab and paclitaxel in women with her2-positive, pik3ca mutant and pik3ca wild-type primary breast cancer - neophoebe. Thirty-Eighth Annual CTRC-AACR San Antonio Breast Cancer Symposium; December 8-12, 2015; San Antonio, TX, USA. doi: 10.1158/1538-7445.SABCS15-P1-14-01.
Received March 13, 2018

Revised April 10, 2018

Accepted April 17, 2018 